\title{
Characterization on AISI 316L Stainless Steel; Boriding, Nitriding and Boriding- Nitriding
}

Gerardo Pérez Mendoza ${ }^{1}$, Noe Lopez Perrusquia ${ }^{1}$, Marco Doñu Ruiz ${ }^{1}$, Lizbeth Melo-Máximo ${ }^{2}$ and Ismael Lopez Velazquez ${ }^{1}$

${ }^{1}$ Universidad Politecnica del Valle de México, Mexico, Distrito Federal, Mexico, ${ }^{2}$ Tecnológico de Monterrey, Mexico, Distrito Federal, Mexico,

The variety of surface treatment processes in 316L stainless steels permits the formation of hard surfaces, with the intention of improve its performance and to be used widely in the industry [1]; However there are few studies and evidence on results of hard surface formation, obtained by a mixture of dehydrated boron paste, salt nitriding and the combination of both processes [2-3]. This study shows the effect of surface treatments on $316 \mathrm{~L}$ stainless steel.

The chemical composition of AISI 316L stainless steel is: $0.03 \% \mathrm{C}, 2.0 \% \mathrm{Mg}, 0.03 \% \mathrm{P}, 0.03 \% \mathrm{~S}, 0.75 \%$ $\mathrm{Si}, 20 \% \mathrm{Cr}, 14 \% \mathrm{Ni}, 4 \% \mathrm{Mo}$. Three surface treatments applied on samples stainless steels: Boriding, Nitriding and Boriding-Nitriding. The boriding process was realized by dehydrated paste in box in a conventional furnace without inert gas, using a mixture of $70 \mathrm{wt} \%$ reused boron and $30 \mathrm{wt} \%$ pure boron at a temperature of $900^{\circ} \mathrm{C}$ for $2 \mathrm{~h}$; next, it was removed out of the furnace to obtain the ambient temperature. The nitriding process was realized in a furnace for salts with of 50wt\% Potassium Nitrate and 50wt\% Sodium Nitrate at $550^{\circ} \mathrm{C}$ for $2 \mathrm{~h}$, continuing with cooling in the salts to $350^{\circ} \mathrm{C}$ for $0.25 \mathrm{~h}$ reaching the ambient temperature out of the salt furnace. The Boriding-Nitriding duplex process was performed; first boriding and second nitriding with the times and temperatures established in this study.

The layers formed on the $316 \mathrm{~L}$ stainless steel surface were then studied using a Scanning Electron Microscope JSM-IT100, to determine the morphology, layer structure and layer thickness. The layers obtained were analyzed by means of a Bruker D8 Advance Diffractometer with a radiation $\mathrm{CuK} \alpha$ wavelength $\lambda=1.54 \mathrm{~A}$ at a speed of $2 \% \mathrm{~min}$.

Figure 1a) shows the formation the boride layers, exhibited a monolayer structure flat $\mathrm{Fe}_{2} \mathrm{~B}$ whit thickness of $5.89 \mu \mathrm{m}$; the EDS analysis shown the presence of B, Cr, N,C. Figure $1 \mathrm{~b}$ ) shows the formation nitride layers, revealed a layer structure flat $\mathrm{Fe}_{3} \mathrm{~N}$ and $\mathrm{Fe}_{3} \mathrm{~N}$ with a thickness of $3.51 \mu \mathrm{m}$ and EDS analysis shown the presence of $\mathrm{Mn}, \mathrm{Cr}$, Ni on layer nitride, Figure 1c) shows the formation the layer by boriding-nitriding, exhibited a multilayer structure flat with a thickness of $26.07 \mu \mathrm{m}$. In addition, a crack is evident in the mixture layer caused by tension and compression stresses from the Boriding-Nitriding process and EDS analysis reveals a high concentration of Oxygen, and also the presence of N,B,Mn,Cr.

Figure 2a) The XRD analysis confirmed the presence of the $\mathrm{Fe}_{2} \mathrm{~B}$ phase and $\mathrm{CrB}, \mathrm{Ni} 3 \mathrm{~B}$ for the boriding process by combination dehydrated boron paste. For Figure 2b) XRD analysis confirmed the presence of a layer formed by the phases $\mathrm{CrN}, \mathrm{Fe}_{4} \mathrm{~N}, \mathrm{Fe}_{3} \mathrm{~N}$ and $\mathrm{CrO}_{3}$ by salt nitriding process. Figure 2c) XRD analysis reveals in the mixture layer, the presence of $\mathrm{Fe}_{4} \mathrm{~N}$ and $\mathrm{B}_{\mathrm{X}} \mathrm{N}$, phases obtained by the boriding-nitriding process. In addition is revealed $\mathrm{Fe}_{2} \mathrm{O}_{3}, \mathrm{FeBO}_{3}$ and $\mathrm{Cr}_{2} \mathrm{O}_{3}$ oxides, caused by the in the salt nitriding process. The boron paste dehydrated mixture shows an effect for the formation of the boride layer. The Salts nitriding produces a combined nitride layer. The combined boriding-nitriding treatment has an influence on the growth and thickness of the multilayer. 

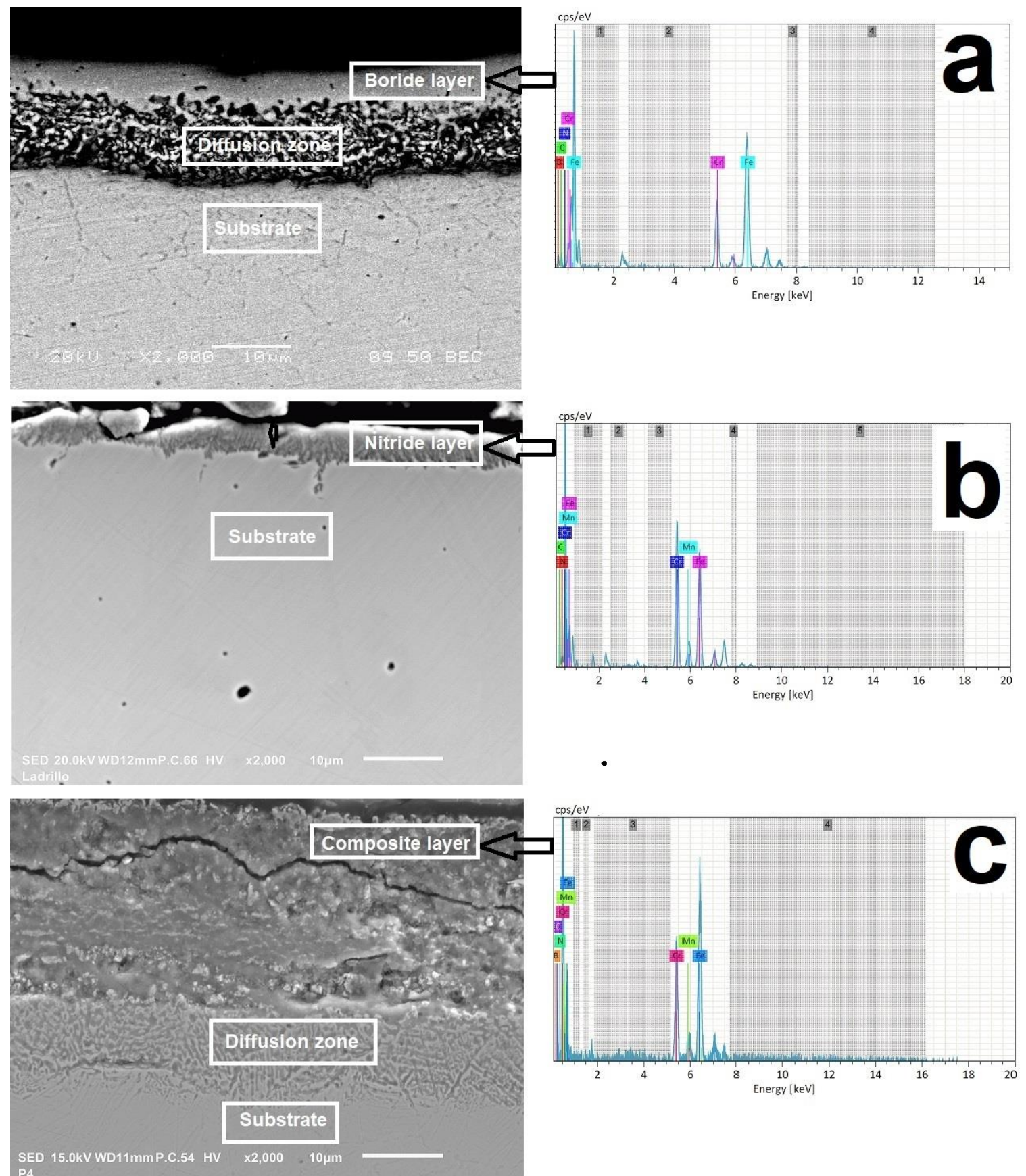

Figure 1. SEM micrograph shows the AISI 316L stainless steel; (a) Layer of Boride at $900^{\circ} \mathrm{C}$ by $2 \mathrm{~h}$, (b) Layer of Nitride of $550^{\circ} \mathrm{C}$ by $2 \mathrm{~h}$ and (c) Layer of Boriding-Nitriding 


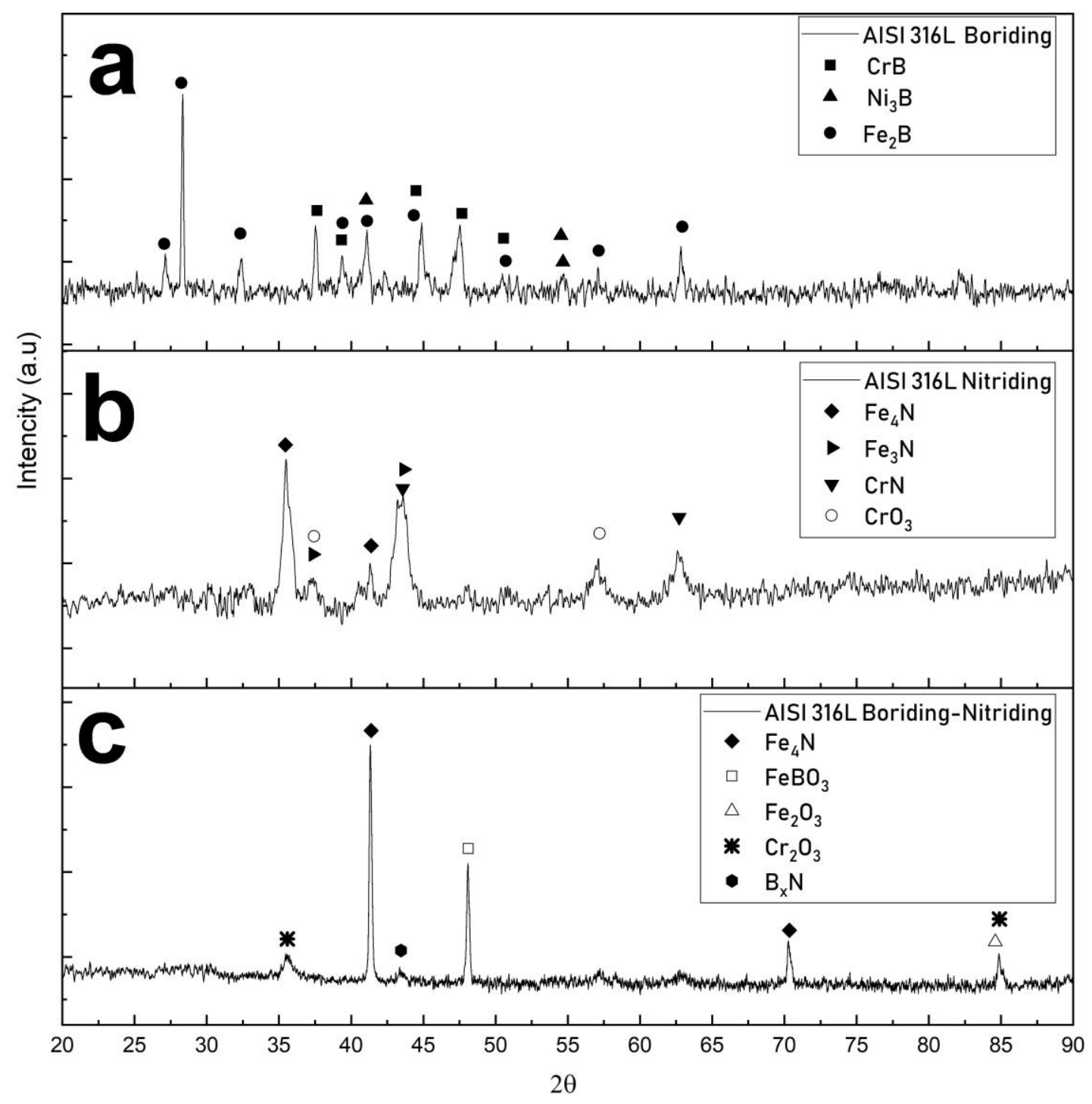

Figure 2. XRD diffraction patterns obtained on surface of AISI 316L stainless steel; (a) Boriding by dehydrated paste, (b) Nitriding in salts and (c) Boriding-Nitriding

References

[1] I. E. Campos-Silva and G.A. Rodríguez-Castro, Thermochemical Surface Engineering of Steels, $1^{\text {st }}$ ed., E.J. Mittemeijer and M.A.J. Somers, Ed., Woodhead-Elsevier Publishing, Cambridge, 2015, p. 651697.

[2] G. Pérez Mendoza et. al., Microscopy and Microanalysis. 25(S2) (2019), p. 2398-2399

[3] O. A. Gómez-Vargas et. al., Microscopy and Microanalysis. 25(S2) (2019), p. 796-797 